\title{
1 La constitución de la ética: la ética del mercado y 2 su crítica
}

\section{The constitution of ethics: the ethics of the market and 4 its critique}

5 A constituição da ética: a ética do mercado e sua crítica

6

\section{Franz J. Hinkelammert ${ }^{1}$}

\section{Resumen}

El artículo propone un análisis del mercado y de la ética del mercado a partir de su propio funcionamiento. Se analiza el tema primero en Platón, después en autores modernos como son, especialmente, Adam Smith, Immanuel Kant, Max Weber y Ludwig Wittgenstein. Se centra en las normas básicas de esta ética: no matarás, no robarás y no estafarás para apropiarse de la propiedad de otros. Se finaliza el artículo con una discusión de las necesidades, la opción por la vida y los juicios vida-muerte en Spinoza y en Marx.

Palabras clave: normas, racionalidad medio-fin, juicios de hecho, juicios de valor, opción por la vida.

\begin{abstract}
The paper proposes an analysis of the market and the ethics of the market based on its own operation. It focuses on the basic rules of this ethic: you will not kill, you will not steal and you will not cheat to appropriate the property of others. I analyze the subject first in Plato, then in modern authors such as Adam Smith, Immanuel Kant, Max Weber and Ludwig Wittgenstein. We end the article with a discussion of the needs, the option for life, and the life-death judgments in Spinoza and Marx.
\end{abstract}

\footnotetext{
${ }^{1}$ Doi: https://doi.org/10.15359/eys.26-60.4

Recibido: 03-09-2021. Reenvíos: 10-11-2021. Aceptado: 29-11-2021. Publicado: 01-12-2021.

${ }^{1}$ Doctor en Economía, correo electrónico: Hinkelammert@hotmail.com, ORCID https://orcid.org/0000$\underline{0001-6315-5171}$
}

El manuscrito pre-publicación es una versión aceptada del artículo previo al proceso final de edición, diagramación y revisión, por lo que puede diferir de la versión final publicada. 
Keywords: norms, means-end rationality, factual judgments, value judgments, choice for life.

\section{Resumo}

$\mathrm{O}$ artigo propõe uma análise do mercado e da ética do mercado com base no seu próprio funcionamento. $\mathrm{O}$ assunto é analisado primeiro em Platão, depois em autores modernos como Adam Smith, Immanuel Kant, Max Weber e Ludwig Wittgenstein. Centra-se nas regras básicas destas éticas: não matarás, não roubarás e não defraudarás a fim de te apropriares dos bens alheios. 0 artigo termina com uma discussão sobre as necessidades, a escolha para juízos de vida e de morte em Spinoza e Marx.

Palavras-chave: normas, racionalidade de fim de linha, juízos de facto, juízos de valor, escolha pela vida.

\section{Introducción}

Quiero hacer aquí un análisis del mercado y de la economía de mercado de una manera poco usual. Se trata de un análisis de la ética del mercado, que de ninguna manera es simplemente una ética referida a los efectos que produce el mercado. Se trata, en cambio, de un análisis de la ética del mercado y de cómo esta ética está presente en el propio funcionamiento de este mercado. Quiero solamente dar algunos ejemplos de esta ética. La ética del mercado tiene tres normas muy básicas, que además son normas éticas cuya validez no se restringe al mercado. Se trata de las normas que prohíben matar al otro para apoderarse de sus propiedades, las normas que prohíben robar y las normas que prohíben la estafa del otro, es decir, que prohíben mentir y engañar. Hay muchas otras normas, sin embargo, estas tres permiten analizar lo que es el problema de la ética del mercado: no matarás, no robarás, no estafarás.

Son normas que aseguran el propio funcionamiento del mercado. Por supuesto, muchas veces estas normas no se cumplen. Pero si no se cumplen en un grado demasiado grande, el propio mercado deja de funcionar y fracasa en su tarea de coordinar el sistema de coordinación del trabajo social. Por esta razón, cada sociedad de mercado intenta asegurar que la violación de estas normas solo ocurra en el grado necesario para poder sostener el mercado.

Max Weber habla de vez en cuando de la ética del mercado. Pero nunca transforma esta ética en objeto de análisis. Eso vale en general también para la mayoría de los economistas. Pero, de hecho, no hace falta concebir algo así como los juicios de valor de Weber, para explicar los valores de la ética del mercado. Basta con querer tener un diagramación y revisión, por lo que puede diferir de la versión final publicada. 
mercado que funcione. Para tenerlo, hay que instalar los valores de la ética del mercado y su instalación no es ningún resultado de juicios de valor. Simplemente es un requisito para hacer posible una institución necesaria.

He tomado como ejemplos de normas de la ética del mercado tres normas del decálogo que aparece en el Antiguo Testamento de la Biblia, en el monte Sión, y que es entregado por Jahvé. De hecho, aquí Jahvé asume estas normas ya existentes y las declara a la vez como normas que él mismo hace suyas. Se necesita este apoyo, porque estas normas están constantemente en conflicto con el interés egoísta del ser humano. Individualmente se puede ganar al violar las normas, pero la ética condena esta actitud. En la Biblia, Jahvé mismo adopta esta posición. Hoy muchas veces argumentamos en el mismo sentido en nombre del bien común.

Quiero ahora ver cómo, en nuestra historia, se desarrolla la comprensión de esta ética del mercado. Quiero verlo primero en Platón, después en autores modernos como son, especialmente, Adam Smith, Immanuel. Kant, Max Weber y Wittgenstein.

\section{La aparición de la ética de la banda de ladrones: Platón y el templo de Jerusalén}

Platón se enfrenta a la crítica de un sofista griego, según el cual siempre sería más racional y exitoso no tener ninguna ética a la cual sujetarse. Platón le responde que, en tal caso, sin ética, ya no se puede actuar siquiera. Hasta una banda de ladrones, dice Platón, necesita una ética, que es una ética muy normal. Sin embargo, la aplican los ladrones solamente en sus relaciones internas, no hacia el exterior. Solamente al cumplir de esta manera con su ética, la banda de ladrones puede tener éxito. Los ladrones de una banda de ladrones no se deben robar ni matar entre sí, para que hacia fuera puedan robar y matar exitosamente.

Platón se enfrenta a un argumento corriente en su tiempo, según el cual "El injusto es inteligente y hábil, y el justo no es ni lo uno, ni lo otro.... El hombre injusto se parece, por consiguiente, al hombre inteligente y hábil y el justo no se parece a éste" (Platón, $\underline{1972}$, p. 1054).

Hace una pregunta sorpresa:

Lo que quería saber yo es si un estado que se hace dueño de otro estado, puede llevar a cabo esta empresa sin emplear la justicia, o si se verá precisado a valerse de ella [...] hazme el favor de decir si un estado, un ejército, o una cuadrilla de bandidos y ladrones, o cualquiera otra sociedad de este género podrían triunfar en sus empresas injustas, si los miembros que la componen violasen, los unos respecto de los otros, todas las reglas de la justicia" (Platón, 1972 p. 1057).

El manuscrito pre-publicación es una versión aceptada del artículo previo al proceso final de edición, diagramación y revisión, por lo que puede diferir de la versión final publicada. 
Aquí aparece la ética de la banda de ladrones. Si no cumple con ciertas leyes, ni la banda de ladrones puede funcionar:

“¿No sería porque la injusticia daría origen a sediciones, odios y combates entre ellos, al paso que la justicia mantendría entre los mismos la paz y la concordia?... ¿no produciría indudablemente el mismo efecto entre los hombres, sean libres o esclavos y no les hará impotentes para emprender cosa alguna en común? [...] Es tal, pues, la naturaleza de la injusticia, ya se encuentre en un estado, ya en un ejército o en cualquiera otra sociedad, que, en primer lugar, la hace absolutamente impotente para emprender nada a causa de las querellas y sediciones que provoca" (Platón, 1972 p. 1058).

La misma polis resulta ahora una gran banda de ladrones. Platón no reflexiona eso mayormente, y deja en este punto sus argumentos. Únicamente pregunta por la perfección de la polis, dado este estado de las cosas.

Se nota enseguida una gran preocupación. Que la polis sea organizada como banda de ladrones no le molesta. Su problema es, cómo evitar que el ejército de la polis se transforme al interior de la polis en otra banda de ladrones, que le robe a la polis. Se imagina, entonces, un sometimiento ideal del aparato militar a la polis y su gobierno, lo que hacen presente a los magistrados.

En esta línea de Platón sigue después el mismo Jesús. Cuando entra en un conflicto con el templo de Jerusalén, choca también con todos los negociantes que operan en este templo, principalmente por la venta de animales que pueden ser usados como sacrificios de parte de los sacerdotes del templo. Sobre este aspecto del templo, Jesús ahora dice que es una: "cueva de ladrones" (Mateo 21.13). Obviamente esta palabra repite de hecho la palabra de Platón de la "cueva de ladrones".

\section{Dos pensadores de la llustración: Adam Smith e Immanuel Kant}

Quiero ahora hacer ver cómo dos de los más importantes pensadores de la llustración del siglo XVIII -el siglo de las luces - enfocan este problema. Primero quiero citar a Adam Smith, el fundador de la ciencia económica. Smith sigue la misma argumentación que había iniciado Platón. Las variaciones que introduce son solamente de importancia secundaria:

"Pero la sociedad nunca puede subsistir entre quienes están constantemente prestos a herir y dañar a otros. Al punto en que empiece el menoscabo, el rencor y la animadversión recíprocos aparecerán, todos los lazos de unión saltarán en pedazos y los diferentes miembros de la sociedad serán por así decirlo disipados y esparcidos por la violencia y oposición de sus afectos discordantes. Si hay sociedades entre ladrones $y$ asesinos, al menos deben

El manuscrito pre-publicación es una versión aceptada del artículo previo al proceso final de edición, diagramación y revisión, por lo que puede diferir de la versión final publicada. 
abstenerse, como se dice comúnmente, de robarse y asesinarse entre ellos. La beneficencia, por tanto, es menos esencial para la existencia de la sociedad que la justicia. La sociedad puede mantenerse sin beneficencia, aunque no en la situación más confortable; pero si prevalece la injusticia, su destrucción será completa" (Smith, 1997, p. 186).

Smith percibe, evidentemente, la ética del mercado como una necesidad imprescindible en cualquier sociedad humana en la que impere el mercado. Insiste que eso vale inclusive para "sociedades entre ladrones y asesinos". Smith habla en cuanto a la necesidad de esta ética de justicia y, de hecho, Smith no menciona otra justicia que esta ética de mercado. Frente a esta justicia, la "beneficencia" es perfectamente secundaria. Con eso rechaza toda concepción de justicia social y su intervención en el mercado. Ni habla de justicia social. La palabra beneficencia suena hasta despreciativa, aunque no la rechaza completamente.

Kant sigue en esta línea también. Kant dice que su ética del imperativo categórico tendría, necesariamente, que ser aplicada en toda sociedad, hasta por un "pueblo de demonios". Dice eso en su libro La paz perpetua:

"El problema del establecimiento de un Estado tiene siempre solución, por muy extraño que parezca, aun cuando se trate de un pueblo de demonios (diablos); basta con que éstos posean entendimiento. El problema es el siguiente: «He aquí una muchedumbre de seres racionales que desean, todos, leyes universales para su propia conservación, aun cuando cada uno de ellos, en su interior, se inclina siempre a eludir la ley. Se trata de ordenar su vida en una constitución, de tal suerte que, aunque sus sentimientos íntimos sean opuestos y hostiles unos a otros, queden contenidos, y el resultado público de la conducta de esos seres sea el mismo exactamente que si no tuvieran malos instintos»" (Kant, 2003, p. 28).

Se trata de la manera de Kant de asumir el argumento de Platón sobre la ética de la banda de ladrones. Ahora no se habla de una banda de ladrones, sino de un pueblo de demonios. Sea la gente mala o buena, de todas maneras, tienen que reconocer la validez de la ética formal, que incluye siempre la ética del mercado.

\section{Ludwig Wittgenstein: el suicidio de la ética}

174 Sin embargo, Wittgenstein formula en sus diarios, antes de su primer libro famoso Tractatus 175 logico-philosophicus, del año 1918, una reflexión que posteriormente no retoma y que abre 176 otras dimensiones posibles de su reflexión de la ética. Se trata del texto siguiente:

"Si el suicidio está permitido, todo está entonces permitido. diagramación y revisión, por lo que puede diferir de la versión final publicada. 
Lo cual arroja una luz sobre la esencia de la ética. Porque el suicidio es, por así decirlo, el pecado elemental.

Y cuando se investiga sobre él, es como cuando se investiga el vapor de mercurio para captar la esencia de los vapores. iAunque acaso el suicidio tampoco sea, por sí mismo, bueno ni malo!" (Wittgenstein, 1986, 10.1.1917)

Para ver toda la dimensión de esta cita, hace falta invertir la primera frase. Entonces diría: Si en una sociedad todo está permitido y no hay acciones prohibidas, eso es suicidio colectivo de esta sociedad. De eso sigue, entonces, efectivamente, lo que Wittgenstein concluye en la cita: Porque el suicidio es, por así decirlo, el pecado elemental. Por tanto, este juicio de negar la existencia de la ética resulta ser un juicio vida-muerte. La renuncia al carácter objetivo de la ética resulta ser la afirmación del suicidio: No hay vida humana social posible sin una $o$ varias éticas que juzguen sobre esta acción.

Wittgenstein no hace esta conclusión. La crítica a Wittgenstein puede empezar precisamente con nuestra cita de Wittgenstein en su forma invertida: Si no hay ética, entonces hay puro suicidio. En nuestro lenguaje más usado, se puede expresar eso mismo como: Si no hay ética, hay caos. Pero caos es solamente otra palabra para la muerte. Por tanto: Si no hay ética, hay solamente muerte. Y esta muerte es a la vez suicidio.

Ética es, entonces, el conjunto ético que hay que tomar para que el ser humano como ser que es parte de una sociedad pueda vivir. Toda sociedad debe tener una ética de este tipo, aunque sea una sociedad extremamente inhumana. Por eso, una sociedad con esclavos tiene esta ética, donde la misma ética entonces establece que la esclavitud no está prohibida. Es la ética de la sociedad griega antigua, de la romana antigua y también de Estados Unidos. hasta el año 1865, año de la liberación de los esclavos. Ni la Alemania Nazi abolió la prohibición del asesinato. Solamente introdujo una excepción: excepto sobre todo judíos y comunistas.

El problema que resulta no es que no haya ética y que esta no pueda ser desarrollada. El problema es cuál es la ética preferible, más humana. Discutir eso necesita también la construcción de mundos perfectos, es decir, obliga a preguntar cuál es la ética perfecta.

\section{Max Weber y su incapacidad de ver el problema}

Lo más llamativo es que, en general, en la literatura positivista, incluida toda la filosofía analítica, ni se discuten en serio estas idealizaciones que ellos efectúan y

El manuscrito pre-publicación es una versión aceptada del artículo previo al proceso final de edición, diagramación y revisión, por lo que puede diferir de la versión final publicada. 
forzosamente tendrían que hacerlo al desarrollar sus teorías empíricas. Hay muchos casos más. Max Weber cuando usa tales argumentos no discute eso y, lo más rápidamente posible, lo deja de lado. Voy a citar el ejemplo que me parece

218 más llamativo:

"Por un lado, los dominados no pueden prescindir del aparato de dominio burocrático ya existente ni sustituirlo por otro, pues se basa en una metódica síntesis de entrenamiento especializado, división de trabajo y dedicación fija a un conjunto de funciones habituales diestramente ejercidas. Si el mecanismo en cuestión [el mecanismo del mercado, $\mathrm{FJH}$ ] suspende su labor o queda detenido por una fuerza poderosa, la consecuencia de ello es un caos, para dar fin al cual difícilmente pueden improvisar los dominados un organismo que lo sustituya. Esto se refiere tanto a la esfera del gobierno público como a la de la economía privada. La vinculación del destino material de la masa al funcionamiento correcto y continuo de las organizaciones capitalistas privadas, organizadas de una manera cada vez más burocrática, va siendo más fuerte a medida que pasa el tiempo, y la idea de la posibilidad de su eliminación es, por tanto, cada vez más utópica" (Weber, 1984, p. 741-742).

241 Lo que resultará es el caos y la utopía imposible. Por tanto, eso es imposible y si es 242 imposible eso, también es igualmente imposible la eliminación de la ética del

En esta cita, Weber critica el programa de los movimientos socialistas de su tiempo, en los cuales se pide, con el socialismo, fundar a la vez una economía sin el uso de dinero. Afirma esta imposibilidad en términos absolutos. En esta cita lo afirma dos veces. Una vez dice: Si el mecanismo en cuestión (el mercado FJH) suspende su labor o queda detenido por una fuerza poderosa, la consecuencia de ello es un caos. Y, luego agrega: La vinculación del destino material de la masa al funcionamiento correcto y continuo de las organizaciones capitalistas privadas [...] va siendo más fuerte a medida que pasa el tiempo, y la idea de la posibilidad de su eliminación es, por tanto, cada vez más utópica.

mercado, porque el mercado no puede funcionar sin esta ética. Creo que este juicio de Weber es cierto, y hoy no hay movimientos socialistas que exijan la eliminación del dinero en el socialismo.

Entonces lo que ocurre con el argumento de Weber es que resulta completamente incompatible con su propia teoría de la metodología de las ciencias, en especial de las ciencias sociales. Él está claramente justificando una ética por juicios de hecho y eso es, según el propio Weber, absolutamente inaceptable. Valores y éticas pueden, según Weber, ser afirmados solamente por juicios de valor y jamás con juicios de hecho. Sin embargo, en el texto citado, Weber lo hace en nombre de juicios de hecho. Si su crítica

El manuscrito pre-publicación es una versión aceptada del artículo previo al proceso final de edición, diagramación y revisión, por lo que puede diferir de la versión final publicada. 
es correcta, como también lo creo, entonces toda su metodología pierde validez y

253 sigue válida la tradición de efectuar tales juicios iniciada con Platón.

254 El resultado de Weber es que su crítica del socialismo no hace de ninguna manera 255 imposible la realización del socialismo, mientras que su crítica sí hace perfectamente 256 inaceptable su propia teoría de la metodología de las ciencias sociales. Y, Weber ni se 257 da cuenta de este problema tan grave.

\section{2. La opción por la vida: el conatus}

259 Cuando Spinoza habla del conatus, define a éste de la siguiente manera: Conatus esse 260 conservandi primum et unicum virtutis est fundamentum [El impulso (conatus) de 261 conservarse es la primera y única base de la virtud] (Spinoza, 1977, pp. 486-487). 262 Significa: El suicidio es el final, la negación, la renuncia de toda virtud.

263 El añade: Nemo potest cupere beatum esse, bene agere et bene vivere, qui simul non 264 cupiat, esse, agere et vivere, hoc est, actu existere. [Nadie puede a la vez querer ser 265 feliz, actuar de manera buena y vivir bien, si no quiere a la vez ser, actuar y vivir, es 266 decir, vivir realmente (sin ser feliz), actuar de mala manera y sin vivir bien] (Spinoza, $267 \quad \underline{1977}$, pp. 484-485)

268 Son las necesidades que las que obligan, no los gustos. Hay que vivir, aunque todavía 269 no se pueda vivir bien. Para mantener posibilidades de vivir bien, hay que poder vivir, 270 aunque se viva mal. Son las necesidades del ser humano, las que hay que satisfacer, 271 no los gustos. Los gustos cuentan, en cuanto no impiden satisfacer necesidades.

272 La pobreza es un problema de necesidades insatisfechas, no de gustos. Detrás de 273 cualquier satisfacción de gustos, aparece el hecho de que toda demanda tiene como 274 origen necesidades y no gustos. La necesidad busca el gusto, siempre en el marco de 275 las necesidades. Estas pueden ser también muy subjetivas y actúan como necesidades 276 que también quieren satisfacer gustos. Pero, en caso de conflictos, siempre deciden 277 las necesidades.

278 Eso es: optar por la vida. Para poder optar por la vida, hay que optar, aunque a uno 279 no le guste la vida que lleva. El suicidio nunca es solución, porque significa renunciar 280 para siempre a soluciones. El suicidio es puro final. Más allá del suicidio solamente se 281 puede imaginar soluciones del tipo religioso.

282 Optar por la vida de uno es solamente posible, optando a la vez por la vida de otros. 283 El emperador romano Calígula decía: Quisiera que todos tuvieran un solo cuello: para 284 cortarlo. Lo que está queriendo no es más que su propio suicidio: nadie puede vivir sin 285 depender de la vida de otros.

El manuscrito pre-publicación es una versión aceptada del artículo previo al proceso final de edición, diagramación y revisión, por lo que puede diferir de la versión final publicada. 
Aunque se quiere vivir bien, hay que vivir mal si no hay la posibilidad de vivir bien. Pero hay que vivir, aunque sea para buscar una buena vida. Según Spinoza, hay que vivir como se puede, para intentar vivir bien. Hay un conatus que obliga a vivir, aunque se viva mal. Claro, sigue la opción del suicidio en el caso que, el vivir sea insoportable como era el caso de miles de judíos, cuando los Nazis los querían llevar a Auschwitz.

291 Sin embargo, ni en este caso, el suicidio es alternativa. Al acabar con todas las alternativas pensables, le quita inclusive al propio suicidio la posibilidad de ser alternativa. Porque para ser alternativa, tiene que transmitir una posibilidad de decidir en favor de una manera de vivir.

Eso llega a un límite, e históricamente ha llegado a este límite muchas veces. En este caso, los pobres y desplazados se levantan, porque no quieren aguantar más y también porque encuentran apoyo y solidaridad en otros, que vienen más bien de clases sociales superiores y que se solidarizan. Estamos hoy viviendo un límite de este tipo que, sin embargo, esta es la primera vez que se levanta realmente una resistencia mundial frente al hecho de que se vive una situación mundial en la cual se nota la presencia de la amenaza de un suicidio colectivo de la propia humanidad. Se trata sobre todo de la crisis del clima.

303 De esta manera, la afirmación de la vida puede desembocar en la revolución de la 304 sociedad. Hoy, la revolución aparece como alternativa posible para el suicidio 305 colectivo de la humanidad, que nos amenaza. Para juzgar sobre eso, hay que mantener 306 en mente el hecho de que las revoluciones no son necesariamente violentas. 307 Necesitamos una alternativa para este suicidio colectivo de la humanidad. Este tipo 308 de alternativas siempre se hacen presentes en imaginaciones de otro mundo perfecto, 309 en relación con las cuales hay que pensar un proyecto histórico correspondiente, que 310 sea efectivamente factible.

\section{3. La producción en el mercado y los juicios vida-muerte}

312 Los juicios que no son juicios medio-fin, que son a la vez juicios de hecho, son juicios 313 vida-muerte. Hay normas muy básicas que se basan en tales juicios vida-muerte. 314 Normas necesarias y obligatorias que están basadas sobre juicios vida-muerte. No 315 matarás es una norma obligatoria, que resulta de juicios de hecho. Eso no vale 316 solamente para la norma, sino también para sus excepciones (por ejemplo: defensa 317 propia). Presuponen el conatus, del cual habla Spinoza. Weber, en cambio, no toma 318 en cuenta estos juicios de hecho, cuando rechaza los juicios de valor como no 319 relevantes para la ciencia. Normalmente Weber ni ve estos juicios de hecho del tipo 320 vida-muerte. Sin embargo, el conatus nace con nosotros. Un ser vivo lo tiene y el ser 321 humano lo tiene también, pero a la vez sabe que lo tiene. El mismo Marx da a estos 322 juicios vida-muerte un lugar central.

El manuscrito pre-publicación es una versión aceptada del artículo previo al proceso final de edición, diagramación y revisión, por lo que puede diferir de la versión final publicada. 
Sobre cada relación medio-fin pesa todo el tiempo un riesgo, inclusive el riesgo de muerte. Por eso la relación medio-fin está siempre conectada con juicios vida-muerte, que son juicios de hecho que no son juicios medio-fin de la razón instrumental. Todo el tiempo resultan juicios que no se orientan por un fin, sino por la relación vidamuerte, que aparece constantemente en el interior de la realización de fines. Por ejemplo: si cruzo una calle con mucho tráfico, persigo cualquier finalidad dentro de un proyecto medio-fin, como puede ser dirigirme a un lugar determinado. Entonces todo el tiempo tengo que evaluar y adaptar esta actividad de cruzar, dependiendo de los peligros que resultan del tráfico. No son consecuencia del cálculo de un fin, sino resultan del problema vida-muerte, que se hace presente todo el tiempo en la persecución del fin y que interrumpe la persecución del fin en ciertas condiciones.

Estos juicios vida-muerte son juicios de hecho igual como los juicios medio-fin. Pero constituyen valores, sin ser juicios de valor en el sentido de Weber. Ya lo hemos visto: no se puede ni atravesar una calle, sin afirmar todo el tiempo el valor de la vida frente a la muerte. La vida tiene que ser tratada como valor, si se quiere realizar cualquier meta de la acción instrumental. Se podría también decir que en este caso la valorización de la vida es uno de los medios para alcanzar la meta, pero eso no cambia

340 el hecho de que hay que respetar la vida como valor. Es un valor necesario para que 341 los juicios medio-fin puedan seguir.

342 No se transforma en una parte del cálculo medio-fin. La posibilidad de la absolutización de este cálculo medio-fin resulta precisamente por la abstracción de la relación vida-muerte. Para que no colapse el mundo de los juicios medio-fin, hay que someter estos juicios constantemente al criterio vida-muerte. Si eso no ocurre, el mundo pasa al suicidio colectivo de la humanidad entera. En eso desemboca lo que se llama la ley de la pauperización del capitalismo, interpretando el capitalismo como el capitalismo salvaje hoy dominante.

349 Hay una voz popular, que expresa muy bien el problema: no cortes la rama del árbol, 350 sobre la cual estás sentado.

351 Marx opera muchas veces con juicios vida-muerte. Quiero solamente mencionar un 352 ejemplo. Se trata del siguiente juicio de Marx, "Por tanto, la producción capitalista 353 sólo sabe desarrollar la técnica y la combinación del proceso social de producción 354 socavando al mismo tiempo las dos fuentes originales de toda riqueza: la tierra y el 355 trabajador" (Marx, 1966, pp. 423-424).

356 Lo que Marx dice aquí es que, debido a una gran arbitrariedad, vigente en la economía 357 capitalista descontrolada, esta economía lleva al suicidio colectivo de la humanidad. 358 Hoy estamos volviendo a esta arbitrariedad capitalista y nos vemos frente a una 359 tendencia mortal. Por supuesto, este suicidio, del cual se trata, es un acto no

El manuscrito pre-publicación es una versión aceptada del artículo previo al proceso final de edición, diagramación y revisión, por lo que puede diferir de la versión final publicada. 
intencional y no es una meta. Al promoverlo, imaginamos que quizás podamos salir bien a pesar de todo. Pero se ve la posibilidad y la amenaza de este suicidio, aunque directamente no es querido. Pero se lo promueve $y$, por lo menos, se sospecha que uno lo está promoviendo. Sin embargo, no se trata de una meta consciente, sino de una inevitable consecuencia de lo que se está haciendo.

En esta dirección, en los últimos cincuenta años han surgido muchas iniciativas, como el Club de Roma (Los límites del crecimiento, 1972), y recientemente ha aparecido el movimiento Fridays for future (FFF) para enfrentarse a la actual crisis de clima.

Que algo se produce y vende en el mercado significa que es técnicamente racional, en el sentido de que es técnicamente factible. Pero eso no implica que sea económicamente racional. Lo mismo vale para toda racionalidad calculada. Siempre entra el criterio vida-muerte.

No se trata de alguna condena moralista de la racionalidad del cálculo del mercado. Se trata, más bien, de recuperarlo como cálculo imprescindible. Pero en el centro del cálculo del mercado debe descubrirse este criterio vida-muerte, sin el cual la humanidad no puede seguir con la propia continuación imprescindible también de este mercado. Todavía, el autor clásico sobre esto es Polanyi (1989).

\section{Referencias}

Kant, I. (2003): La paz perpetua. Biblioteca Virtual Universal. Disponible en: 89929.pdf (biblioteca.org.ar)

Marx, K. (1966); El Capital. Fondo de Cultura Económica, Tomo I. México.

Platón. 1972. Diálogos. La República o el Estado (1972). EDAF, Madrid.

Polanyi, K. (1989); La Gran Transformación. Piqueta, Madrid.

Smith, A. (1997); La teoría de los sentimientos morales. Alianza, Madrid.

Spinoza, B. (1977); Die Ethik. Reclam, Stuttgart.

Weber, M. (1984); Economía y Sociedad, Fondo de Cultura Económica. México.

Wittgenstein, L. (1986); Diario Filosófico. Editorial Planeta-De Agostini, S.A., Barcelona.

El manuscrito pre-publicación es una versión aceptada del artículo previo al proceso final de edición, diagramación y revisión, por lo que puede diferir de la versión final publicada. 